\title{
Investigation of Individual Perception and Health Behavior towards Covid-19 Pandemic
}

\author{
İsa GÜL ${ }^{1}$, Yunus Emre KUNDAKCI ${ }^{2}$
}

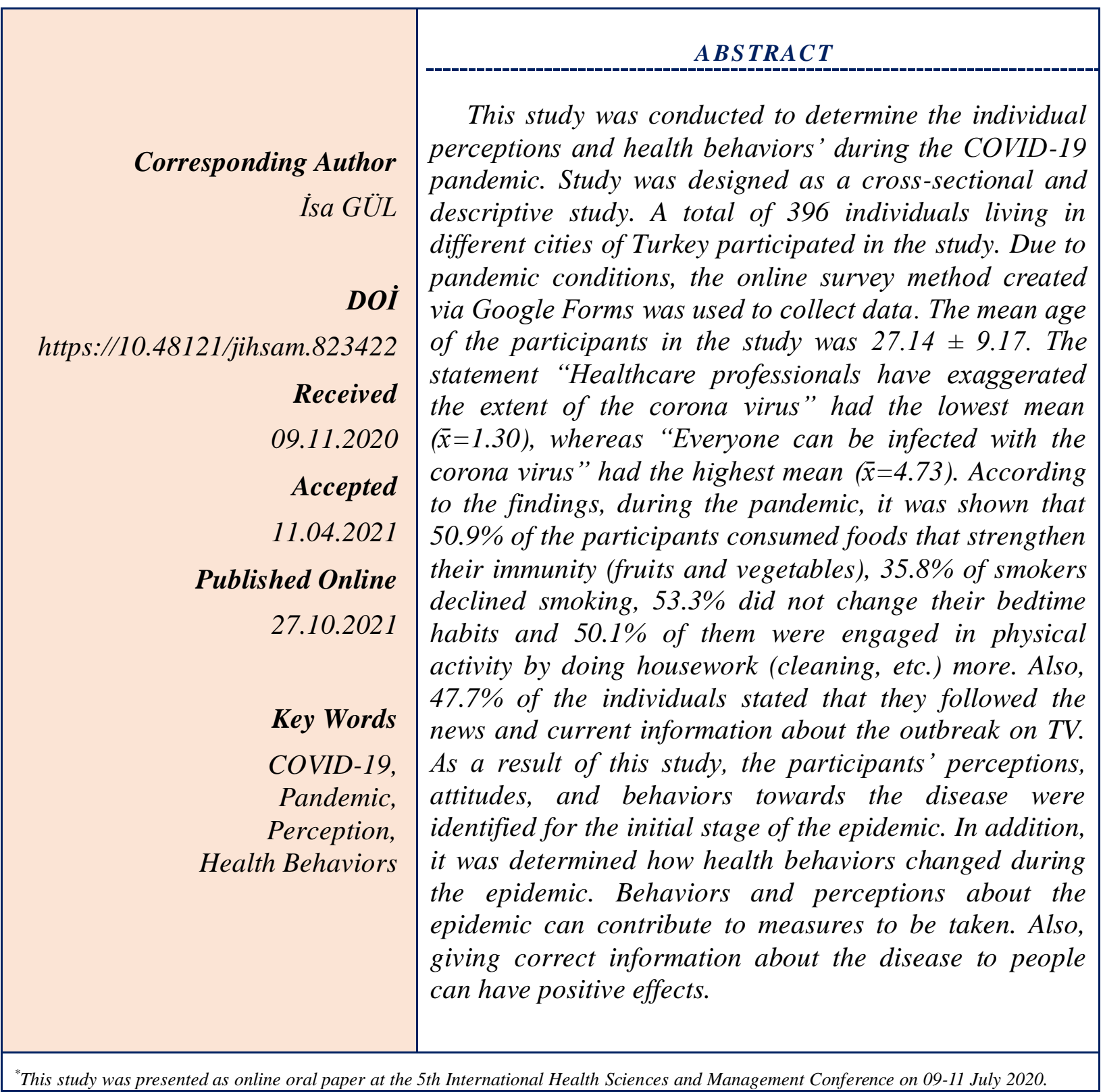

${ }^{1} \mathrm{PhD}$, Assistant Professor, Health Management Department, Faculty of Health Sciences, Afyonkarahisar Health Sciences University, Afyonkarahisar. isagu1233@mail.com / Orcid: 0000-0002-9419-4816

2 Lecturer, Physiotherapy and Rehabilitation Department, Faculty of Health Sciences, Afyonkarahisar Health Sciences University, Afyonkarahisar. y.emre.kndkc@ gmail.com / Orcid: 0000-0002-2006-9940 
A new type of coronavirus (SARS-CoV-2) that causes disease in the human population has been detected in Wuhan, Hubei province, China in 2019. As the disease spread to many countries and reached more serious dimensions, the whole world faced a new pandemic known as COVID-19 (Özdin \& Bayrak Özdin, 2020). Intense infectious disease periods constitute public health problems for society socially, economically, and culturally (Demiray \& Çeviker, 2020; Yang \& Wang, 2020).

It is necessary to reveal the effects of COVID-19 by investigating the characteristics of individuals such as age, gender, region of residence, attitude, and behavior. Studies mostly show that the disease is demographically more risky in elderly people and is associated with comorbidities in type-2 diabetes, hypertension, and cardiopulmonary patients, and preventive measures have to be taken more seriously in these conditions. Moreover, healthcare workers are more at risk as they come into contact with patients (Auwaerter, 2020; Budak \& Korkmaz, 2020; Chen et al., 2020; Dong et al., 2020; Ferguson et al., 2020; WHO, 2020).

In studies involving the problems related to early predictions and responses regarding the COVID-19 epidemic, it was emphasized that the society should be informed correctly, the importance of the disease should be emphasized and the measures to be taken should be planned quickly and accurately. On the other hand, it was stated that due to the exaggerated information, non-evidence-based measures, and recommendations, the individuals in the community created either panic and fear or relaxation related to COVID-19 (Ioannidis, 2020).

There are many questions and theories regarding COVID-19. Why did this virus appear, who is involved? Some people think that the virus is not real. There are conspiracy theories against COVID-19 vaccine considering it as a Chinese biological weapon, or saying that the virus was accidentally released by
China, or that the virus is part of global capital and population reduction projects (Khan et al., 2020; Miller, 2020; Y1lmaz, 2020). These conspiracy theories can lead to harmful consequences for humans (Bavel et al., 2020). Bats are the natural hosts of this disease and some believe that if wild animals are not treated well, humans may be punished by nature (Yang \& Wang, 2020). Environmental conditions such as climate, air and nature pollution are linked to this disease and even increase deaths. Although we have been trying to predict what the new world will be after the pandemic, we do not certainly know yet (Frontera et al., 2020; Isphording \& Pestel, 2020).

Extensive studies are in progress evaluating the behavior and social response towards COVID-19 in humans. In these studies, issues that can help reduce the impact of the current epidemic such as emotion and risk perceptions, prejudice and discrimination, panic effect, social and cultural contexts, culture and information communication in individuals during the pandemic are discussed (Bavel et al., 2020). Measures taken against the epidemic differ in each country. Culturally individual effects of differences between countries in the number of cases and deaths, information sources, pandemic prevention policies, and many other similar issues should be revealed. At the same time, exposing and understanding social behavior mechanisms regionally can contribute to a better response to outbreaks at the national and local levels (Jarynowski et al., 2020). Individuals' perceptions of diseases that take pandemic-like life out of their normal course and their health behaviors in this process are very important in terms of protecting and improving health. In order to control the epidemic, besides the way individuals perceive the disease in the society, health behaviors such as smoking, sleep, physical activity and nutrition during the epidemic process are among the issues that should be taken into consideration in terms of public health. In this study, it is aimed to reveal the perceptions and behaviors of individuals in Turkish society during the pandemic period by analyzing them.

MATERIALS AND METHODS

\section{Study design, setting, and sampling}

This study aimed to examine individual perceptions and behaviors towards the COVID-19 outbreak. It was designed as a descriptive and crosssectional study. The participants of the study group consisted of individuals residing in different cities of Turkey and over 18 years of age. This study was carried out by reaching only 396 individuals due to pandemic conditions. The data were obtained through the online survey method "Google Forms" between 1 April 2020 and 6 April 2020. The online survey link was delivered to the participants through social media channels (WhatsApp, Facebook, Instagram, etc.). The study also complies with the Helsinki Declaration (2013) ethical rules. Participants were included in the study voluntarily and willingly. Before accessing the questionnaire form, the participants were given information about the purpose of the study and were informed that they could refuse to fill in the questionnaire at any time and access the questionnaire if they give their consent. 


\section{Data collection and study procedure}

In the research, an online questionnaire form was used as the data collection tool. The questionnaire form consists of two parts: demographic information and "COVID-19 Perception and Behavior Questionnaire".

Demographic Information: Demographic information included age, gender, marital status, place of residence, educational status, smoking status, and chronic illness of the individuals participating in the study.

COVID-19 Perception and Behavior Questionnaire: In order to determine the perceptions and behaviors of the participants towards COVID-19, a questionnaire form was created using Cirakoglu's (2011) study and literature knowledge. In this form, there were 31 statements regarding the following: the importance of COVID-19 disease and threat perception, perception of the causes of the emergence of the disease, beliefs about COVID-19, personal protection, and the effects of the disease. The level of agreement with these statements has a likert rating of " $1=$ strongly disagree", " $5=$ strongly agree". In addition, there are 5 questions in order to determine the behavior of individuals to follow the news about smoking, sleep patterns, diet, physical activity and the epidemic during the epidemic. In this study, the Cronbach Alpha value of 31 expressions was found to be 0.75 . IBM SPSS version 24 statistical package program was used to analyze the data. The frequency, arithmetic average and standard deviation values of the obtained data are described. The arithmetic mean ranges based on the evaluation of the study results, 1.00-1.80; "strongly disagree", 1.81-2.60; "disagree", 2.61-3.40; "undecided", 3.41-4.20; "agree" and 4.215.00; "strongly agree" (Damgac1 \& Aydın, 2013; Ziemba, 2020).

\section{RESULTS}

The average age of 396 individuals participating in the study was $27.14 \pm 9.17 .66 .2 \%$ of the participants were women, $64.6 \%$ were single, $71.7 \%$ were undergraduate graduates, $32.1 \%$ were living at home with four people during the pandemic period, $23.2 \%$ were smoking, $61.6 \%$ were residing in the city center,
$11.9 \%$ had a chronic disease and $29.3 \%$ had chronic patients who were over 60 years old in their family.

The responses of the participants to the statements in the questionnaire about "Importance of COVID-19 and Threat Perception" are presented in Table 1.

Table 1. Importance of COVID-19 and threat perception

\begin{tabular}{lcc}
\hline Statements & $\overline{\mathrm{X}}$ & $\mathrm{SS}$ \\
\hline The coronavirus is not as dangerous as it is said. & 1.99 & 1.44 \\
The media is exaggerating the coronavirus outbreak. & 1.75 & 1.07 \\
Healthcare professionals are exaggerating the coronavirus outbreak. & 1.30 & 0.70 \\
COVID-19 is a curable disease. & 2.87 & 1.28 \\
COVID-19 is a deadly disease. & 3.83 & 1.14 \\
COVID-19 can infect anyone. & 4.73 & 0.62 \\
COVID-19 is an easily transmitted disease. & 4.69 & 0.66 \\
COVID-19 affects women and men equally. & 3.66 & 1.28 \\
\hline
\end{tabular}

As shown in Table 1, the statement "Healthcare professionals are exaggerating the coronavirus outbreak" ( $\overline{\mathrm{x}}=1.30 \pm 1.44)$ has the lowest average value, while the expression "COVID-19 can infect everyone" is the statement with the highest average value $(\overline{\mathrm{x}}=4.73 \pm 0.62)$. When the table is evaluated, the participants think that the coronavirus is dangerous and that the media or healthcare professionals do not exaggerate the epidemic. In addition, the participants responded at the level of agreeing to the statements that this disease is fatal, can be easily transmitted to anyone, and affects people regardless of gender. The statement "COVID-19 is a curable disease" has an average at the undecisive level.

The responses of the participants to the statements in the questionnaire regarding "Perception of the cause of COVID-19 and beliefs toward COVID-19" are presented in Table 2. 
Table 2. Perception of the cause of COVID-19 and beliefs toward COVID-19

\begin{tabular}{lcc}
\hline Statements & $\overline{\mathrm{X}}$ & $\mathrm{SS}$ \\
\hline The coronavirus originated from wild animals such as bats that the Chinese ate. & 3.47 & 1.34 \\
The coronavirus was produced as a biological weapon. & 2.90 & 1.36 \\
This epidemic occurred naturally. & 2.67 & 1.35 \\
This pandemic is part of a large coronavirus trial. & 2.78 & 1.29 \\
This disease is a political game of developed countries. & 2.82 & 1.35 \\
The cause of this epidemic is the efforts of some countries to sell drugs and vaccines. & 2.67 & 1.30 \\
These kinds of epidemics are an effort to balance nature. & 2.76 & 1.28 \\
Such epidemics are a punishment given by the Creator against society's departure from religion. & 2.87 & 1.49 \\
This epidemic is a wrath of the Creator against social degradation. & 2.93 \\
The coronavirus is the new world order project of a higher mind in the world. & 2.45 \\
The coronavirus emerged to balance the world population and food sources. & 1.27 \\
The coronavirus emerged to liquidate the elderly who could not adapt to the digital world. & 2.48 & 1.24 \\
\end{tabular}

When Table 2. is evaluated, the statement "The coronavirus originated from wild animals such as bats that the Chinese ate" is the statement with the highest average $(\overline{\mathrm{x}}=3.47 \pm 1.34)$ and the participants responded at the level of agree with this statement. On the other hand, the statement "The coronavirus emerged to liquidate the elderly who could not adapt to the digital world" has the lowest average $(\overline{\mathrm{x}}=2.15$ \pm 1.30 ) and reflects the opinion at the level of disagree. Statements about the new world order project and the balance of population-food resources among the beliefs about coronavirus were evaluated with the response at the level of disagree. Other statements have average values at the undecision level.

The responses of the participants to the expressions in the questionnaire regarding "Personal protection measures from COVID-19" are presented in Table 3.

Table 3. Personal protection measures from COVID-19

\begin{tabular}{lrr}
\hline Statements & $\overline{\mathrm{X}}$ & $\mathrm{SS}$ \\
\hline If I pay attention to my personal hygiene, the coronavirus will not infect me. & 3.26 & 1.20 \\
This disease will not affect me if I do physical activity. & 2.43 & 1.17 \\
If I pay attention to my diet, this disease will not affect me. & 2.91 & 1.23 \\
This disease will not affect me if I wear a mask. & 2.32 & 1.12 \\
This disease will not affect me if I wear gloves. & 2.37 & 1.11 \\
It is sufficient for everyone to wash their hands frequently to stop the epidemic. & 2.75 & 1.19 \\
\hline
\end{tabular}

According to Table 3, the average of the statement "If I pay attention to my personal hygiene, the coronavirus will not infect me" $(\overline{\mathrm{x}}=3.26 \pm 1.20)$ is the highest, the average of the expression "This disease will not affect me if I wear a mask" ( $\bar{x}=2.32 \pm 1.12)$ has the lowest value. The statements about wearing masks, wearing gloves and doing physical activity are at the level of disagree, and the average of the statements about paying attention to nutrition and washing their hands frequently to stop the epidemic is at the level of undecision.

The responses of the participants to the statements in the questionnaire about "The effects of COVID-19 and the environment" are presented in Table 4.

Table 4. Effects of COVID-19 and the environment

\begin{tabular}{lcc}
\hline Statements & $\overline{\mathrm{X}}$ & $\mathrm{SS}$ \\
\hline The coronavirus vaccine will prevent the spread of the disease. & 3.40 & 1.18 \\
A more digital world will emerge after this epidemic. & 3.13 & 1.18 \\
The effect of the coronavirus will decrease in the summer months. & 3.11 & 1.13 \\
The coronavirus will have a positive effect on cleaning the polluted nature and the environment. & 3.72 & 1.17 \\
The coronavirus will reduce air pollution. & 3.68 & 1.25 \\
\hline
\end{tabular}

According to Table 4, the average value of the statements "The coronavirus will have a positive effect on cleaning the polluted nature and the environment" is $(\overline{\mathrm{x}}=3.72 \pm 1.17)$, while the average value of the expression "The effect of the coronavirus will decrease in the summer month" was determined as $(\bar{x}=3.11 \pm 1.13)$. While the statement about the
COVID-19 vaccine had an average close to the level of agree, the participants responded to the statements about the emergence of a more digital world than the epidemic and the decrease in the effects of the epidemic in the summer. 
During the COVID-19 pandemic, participants' sleep patterns, smoking, feeding, and physical activity behaviors, as well as their behavior to follow the news about the disease, were shown in figures.

Figure 1. Quarantine during COVID-19 outbreak: Information Sources $(\mathrm{N}=396)$

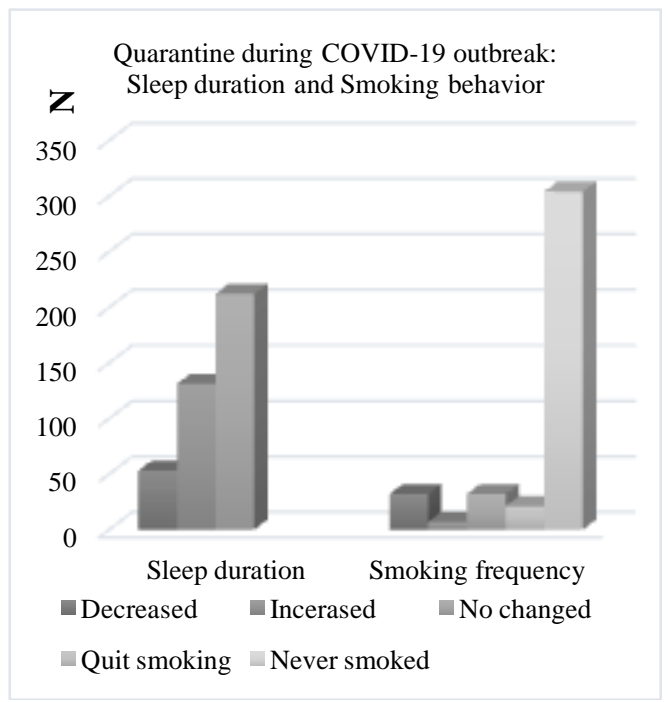

During the pandemic, $34.8 \%$ of participants reported reduced smoking, while $34.8 \%$ reported no change in the frequency of smoking. Furthermore, $7.6 \%$ of the participants stated that they increased smoking and $22.8 \%$ gave up smoking during the pandemic period. When the responses were examined, it was determined that $53.5 \%$ of the participants had no change in their sleep duration, $33.1 \%$ slept more and $13.4 \%$ slept less.

Figure 2. Quarantine during COVID-19 outbreak: Information Sources $(\mathrm{N}=396)$

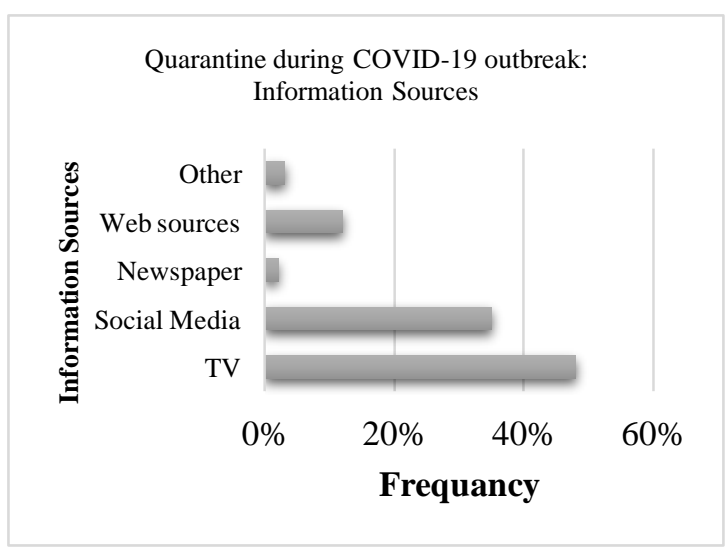

Of the participants included in the study; $48 \%$ stated that they received news and developments about COVID-19 from TV, 35\% from social media (Facebook, Instagram, Twitter, etc.), 12\% from internet sources other than social media, 2\% from newspapers, and 3\% from other sources (magazines, etc.).

Figure 3. Quarantine during COVID-19 outbreak: changes in diet and physical activity (multiple options are marked)

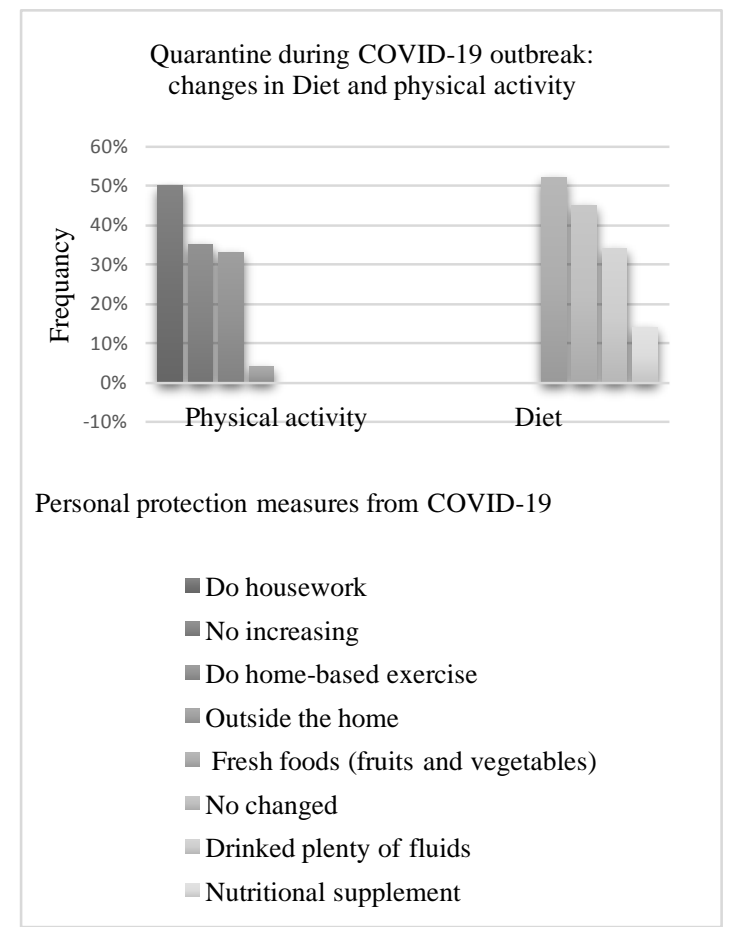

During the pandemic period, the nutritional style was examined; $52.3 \%$ of the participants $(\mathrm{N}=207)$ were eating more immune-strengthening foods (fruits, vegetables, etc. $), 45.2 \%(\mathrm{~N}=179)$ did not change diet style, $34.3 \%(\mathrm{~N}=136)$ consumed plenty of fluids, $14.4 \%(\mathrm{~N}=57)$ used supplements containing vitamins and minerals to strengthen immunity.

When physical activity behavior is examined during the COVID-19 period; $50 \%$ of the respondents ( $\mathrm{N}=198$ ) stated that they did housework (such as cleaning) by paying more attention to physical activity, \%33.3 ( $\mathrm{N}=132)$ by performing physical activity by doing exercises that can be done at home, $4 \%(\mathrm{~N}=16)$ preferred to be out of the house to do physical activity, and 35\% ( $\mathrm{N}=138)$ showed no effort to increase physical activity. 


\section{DISCUSSION}

The COVID-19 pandemic is a global threat that can have biological, behavioral, emotional, and social impacts. Individual behavior and perception have been very important to control the spread of COVID-19, especially during the beginning of the epidemic. Determining the level of these behaviors and perceptions in people living in different cultures or countries provides valuable information for the protection of public health. In addition, individuals perceptions and behaviors towards the pandemic can provide insight for the measures to be taken against new epidemics that may occur in the future.

In this study, the participants agreed that the coronavirus is a dangerous disease and that the media and healthcare professionals are not actually exaggerating the epidemic.In addition, participants stated that COVID-19 is a deadly disease, can be easily transmitted to anyone and affects people regardless of gender.The effects of COVID-19 on society began to be evaluated during the initial stages. In studies conducted in Hong Kong, it was determined that there was a high level of risk perception in the society against COVID-19 (Chan et al., 2020; Kwok, Li, Chan, et al., 2020). Individuals stated that they were worried about the COVID-19 outbreak, that the disease could be transmitted to them, that the symptoms caused by the disease were severe and their daily routines were disturbed (Chan et al., 2020; Kwok, Li, Chan, et al., 2020).

In our study, the participants stated that agree with the statement that COVID-19 disease is caused by wild animals such as bats that the Chinese eat. In addition, the participants replied that they do not agree with the statements about the coronavirus emerging for the purpose of liquidation of the elderly, the new world order and the balance of population-food resources. The average value of the other expressions remained at the level of indecision. Coronaviruses closely related to SARS-CoV are typically found in bats ( $\mathrm{Li}$ et al., 2005). The coronavirus is believed to originate from wild animals in the Huanan market in Wuhan, China. It has been stated in studies that bats, snakes, and pangolins are potential coronavirus carriers (Yang et al., 2020). While bats are likely natural hosts of coronavirus, the specific bat species that serves as the natural host is not yet known. Moreover, bats and their droppings are often used in traditional Chinese Medicine (Wassenaar \& Zou, 2020). On the other hand, many people believe that the virus was created in a laboratory or deliberately developed to "reduce the population" as the secret plan of the "new world order" (Imhoff \& Lamberty, 2020). Another view is that COVID-19 is produced for the sale of vaccines and is a part of projects such as economic, biological, and psychological warfares or global capital and population reduction (Y1lmaz, 2020). There are studies showing high levels of belief in conspiracy theories by society (Patsali et al., 2020). Seeing $5 \mathrm{G}$ as the reason for COVID-19 is a conspiracy theory that is especially pitched by social media users and popularized in January (Ahmed et al., 2020). In one study in Greece, $29 \%$ of participants believed that COVID-19 was a laboratory product, $25 \%$ believed that the spread was a covert action, and $24 \%$ believed that it had been developed as a biological weapon (Kaparounaki et al., 2020).

In this study, statements about wearing a mask, wearing gloves and doing physical activity are at the level of disagree; when paying attention to personal hygiene, the average of the statements about not contaminating the disease, paying attention to nutrition and washing their hands frequently to stop the epidemic had the answers at the level of indecision. Given the potential for airborne transmission of the virus, the necessity of wearing a protective mask arises. The indirect spread of the virus from contaminated surfaces is also possible. Frequent handwashing to prevent particles descending onto surfaces is a rational approach to wearing protective gloves, and disinfecting surfaces (Straif-Bourgeois \& Robinson, 2020). Therefore, the surgical masks, eye protectors and gloves can be considered personal protective equipment (Balachandar et al., 2020). A study in the Philippines found that $82.2 \%$ of the participants washed their hands to prevent disease, $49 \%$ wore face masks, and $44.4 \%$ used hand sanitizer. Also in the pandemic, $89.9 \%$ of the participants were seen to wash their hands more often (Lau et al., 2020).

In this study, the participants think that COVID-19 will contribute positively to air pollution, cleaning the polluted nature and the environment. In addition, while the participants responded with an average close to the level of I agree with the statement about the COVID-19 vaccine, they responded to the statements about the emergence of a more digital world than the epidemic and the reduction of the effects of the epidemic in the summer. In the current case, no vaccine or effective antiviral drug has been found that can be used worldwide to combat the disease. Currently, vaccine production and implementation are said to be on the agenda for the next few years (Anderson et al., 2020). Another issue that is difficult to predict in the early stages of COVID-19 is the environmental changes in the aftermath of the pandemic. On one hand, it is thought that the environment will be more polluted by the interference with nature due to the large consumption of medical material wastes such as disposed masks and gloves, and on the other hand, it is thought that the environment will be less polluted since people are staying at home due to isolation (Saadat et al., 2020). The high level of air pollution in northern Italy also has been assessed as an additional factor to the high mortality rates recorded in that region (Conticini et al., 
2020). The COVID-19 outbreak has changed the air quality in many cities around the world. It has been stated that in many countries such as USA, China, Italy, Spain and the UK, there was a decrease in carbon emissions due to the disruption of industrial activities and transportation systems and the decrease in coal use in factories during the epidemic period. This has led to an increase in the amount of better quality air (Ficetola \& Rubolini, 2020; Saadat et al., 2020). In Venice, Italy, it is stated that as the number of tourists decreases, the water-polluting factors decrease and the water channels become cleaner (Saadat et al., 2020).

In our survey, $48 \%$ of the respondents reported that they followed the news and developments related to COVID-19 from TV, and 35\% from social media (Facebook, Instagram, Twitter, etc.). In a survey conducted in the Philippines, $85.5 \%$ of the respondents reported receiving information about COVID-19 from TV, $56.1 \%$ from radio, $20.7 \%$ from social media (Facebook, Instagram, etc.) (Lau et al., 2020). In another study conducted in Nigeria, the major sources of information on COVID-19 came to the fore as internet/social media $(55.7 \%)$ and TV (27.5\%) (Reuben et al., 2020).

Our research found that during the COVID-19 pandemic, $53.5 \%$ of participants had no change in sleep duration and $33.1 \%$ slept more. Despite the many negative results of quarantine processes in the pandemic, it was stated that it might have a positive effect on improving sleep quality (Altena et al., 2020). It has also been noted that social isolation provided a window of opportunity for individuals to develop and maintain healthy and quality bedtime habits (Arora \& Grey, 2020). A study in Italy reported that individuals spent more time in bed but had lower sleep quality (Cellini et al., 2020). Another study carried out in Italy found that individuals' sleep hours increased, especially during quarantine (Di Renzo et al., 2020).

During the COVID-19 pandemic, $34.8 \%$ of the participants reported a decrease in cigarette use, while $34.8 \%$ reported a change in the frequency of smoking. In a survey conducted in the Netherlands, $14.1 \%$ of the smokers overall reported smoking less due to the COVID-19 pandemic, while $18.9 \%$ of the smokers reported smoking more (Bommelé et al., 2020). On the other hand, a study conducted in Italy found that during the pandemic, $3.3 \%$ of the smokers quit smoking (Di Renzo et al., 2020). A survey in Poland reported that $40 \%$ of smokers did not change their smoking frequency during quarantine, $14.8 \%$ were unsure whether their smoking habits were affected and 45.2\% smoked more (Sidor \& Rzymski, 2020).

During the pandemic, $52.3 \%$ of the participants reported that they consumed immunity-enhancing nutrients (fruits, vegetables, etc.), $34.3 \%$ consumed plenty of fluids, and $14.4 \%$ used vitamin-mineralcontaining reinforcing drug-like products to strengthen immunity. While nutrition strengthens the immune system, some vitamins such as Vitamin C, proper and healthy eating can help improve the immune system (Aman \& Masood, 2020). In addition, during the pandemic period, it is emphasized that a balanced diet containing high amounts of antioxidants and vitamins is essential for human health. In some cases, taking vitamin and mineral supplements can also help (Mattioli et al., 2020). A study in Italy found that during quarantine, $37.4 \%$ of the participants ate more healthy foods (fruits, vegetables, nuts and legumes) (Di Renzo et al., 2020). Another study in the Philippines found that $32.7 \%$ of the participants took vitamins and herbal drugs (Lau et al., 2020).

It is noteworthy that in the pandemic, $50 \%$ of the participants did household chores (cleaning, etc.) with more interest in physical activity, $33.3 \%$ of them increased physical activity by doing the exercises can be done at home. Lack of access to gyms, parks, and a number of other recreational facilities due to quarantine and social isolation measures had a negative impact on individuals' physical activity levels (Arora \& Grey, 2020). Home-based exercise practices, especially during the pandemic period, are among the types of physical activity that can be preferred (Peçanha et al., 2020). A study in Chile during the pandemic period found that $51.2 \%$ of men and $57.8 \%$ of women had reduced levels of physical activity (Reyes-Olavarría et al., 2020). In the outbreak, opportunities to exercise have been limited as most people are isolated in their homes. A study conducted in Wuhan reported that approximately $69.6 \%$ of participants had less physical exercise ( $\mathrm{Fu}$ et al., 2020).

\section{CONCLUSION}

In this study, we aimed to demonstrate the perception of COVID-19 pandemic and health behaviors (such as physical activity, nutrition, smoking) of 396 participants living in different cities of Turkey. In our research, the participants stated that COVID-19 is a significant and life-threatening disease, that the virus is caused by wild animals such as bat, and that they did not adequately agree with the conspiracy theories directed at COVID-19.
Furthermore, the participants think that environment and nature will be cleaner with the outbreak.

Our findings found that $33.1 \%$ of the respondents slept more and $13.4 \%$ slept less. During this period, $34.8 \%$ of the participants stated that they had reduced their smoking, while $22.8 \%$ stated that they had quit smoking. $48 \%$ of the participants watched the news and developments about COVID-19 on TV, while 207 participants viewed immunity-enhancing foods (fruits, 
vegetables, etc.).) stated that he consumed. 198 participants are housekeepers (cleaning etc.) he was more interested in physical activity.

The COVID-19 outbreak has deeply and differently affected all segments of the society, especially the health. It may be necessary to measure the disease perception of individuals in various time periods while the pandemic continues. Because, since the beginning of the pandemic, people's perceptions about the disease can also determine the measures for the disease, although it varies personally. By measuring perceptions, policy makers can make more accurate decisions in controlling the pandemic.
It is seen that there are changes also in people's health behaviors during the COVID-19 process. In a process where human health is under threat like a pandemic, adopting positive health behaviors has become important. Positive behaviors such as adequate and proper nutrition, physical activity and adequate sleep are necessary to stay healthy. Revealing the health behaviors of individuals during the pandemic process guides the presentation of preventive and health-promoting services. In order to minimize the effects of the pandemic, it is recommended to inform individuals about physical activity, nutrition, sleep and increase awareness.

\section{Limitations}

This study had some limitations. It was conducted by reaching only 396 individuals due to pandemic conditions. The data was obtained through the online survey method "Google Forms". The average age of the individuals involved in our research could be described as young. Considering that young people and middle age groups use technological devices more, it can be stated that these groups were more likely to respond to the online survey.
We also tried to present the results through statements because there was no measurement scale that directly measured perceptions, and behaviors towards COVID-19. Our study also had some strengths. The first COVID-19 case in Turkey was reported on 10 March 2020. This investigation was carried out as soon as 20 days after the first case was reported. This is why it was valuable in terms of the perception and behavior of individuals at the beginning stage of the epidemic in Turkey.

\section{REFERENCES}

1. Ahmed, W., Vidal-Alaball, J., Downing, J., \& Seguí, F. L. (2020). COVID-19 and the 5G conspiracy theory: social network analysis of Twitter data. Journal of Medical Internet Research, 22(5), e19458.

2. Altena, E., Baglioni, C., Espie, C. A., Ellis, J., Gavriloff, D., Holzinger, B., Schlarb, A., Frase, L., Jernelöv, S., \& Riemann, D. (2020). Dealing with sleep problems during home confinement due to the COVID- 19 outbreak: Practical recommendations from a task force of the European CBT- I Academy. Journal of Sleep Research, e13052.

3. Aman, F., \& Masood, S. (2020). How Nutrition can help to fight against COVID-19 Pandemic. Pakistan Journal of Medical Sciences, 36(COVID19-S4).

4. Anderson, R. M., Heesterbeek, H., Klinkenberg, D., \& Hollingsworth, T. D. (2020). How will country-based mitigation measures influence the course of the COVID-19 epidemic? The Lancet, 395(10228), 931-934.

5. Arora, T., \& Grey, I. (2020). Health behaviour changes during COVID-19 and the potential consequences: A mini-review.

6. Auwaerter, P. M. D. (2020). Coronavirus COVID-19 (SARSCoV-2).

https://www.hopkins guides.com/hopkins/view/Johns_Hopkins_ ABX_Guide/540747/all/Coronavirus_COVID_19__SARS_Co V_2

7. Balachandar, V., Mahalaxmi, I., Kaavya, J., Vivekanandhan, G., Ajithkumar, S., Arul, N.,

8. Singaravelu, G., Kumar, N. S., \& Devi, S. M. (2020). COVID 19: emerging protective measures. Eur Rev Med Pharmacol Sci, 24(6), 3422-3425.

9. Bavel, J. J. V., Baicker, K., Boggio, P. S., Capraro, V., Cichocka, A., Cikara, M., ... \& Drury,

10. J. (2020). Using social and behavioural science to support COVID-19 pandemic response. Nature Human Behaviour, 112

11. Bommele, J., Hopman, P., Walters, B. H., Geboers, C., Croes, E., Fong, G. T., Quah, A. C.,
12. \& Willemsen, M. (2020). The double-edged relationship between COVID-19 stress and smoking: Implications for smoking cessation. Tobacco Induced Diseases, 18.

13. Budak, F., \& Korkmaz, S. (2020). Covid-19 Pandemi Sürecine Yönelik Genel Bir Değerlendirme: Türkiye Örneği. Sosyal Arastırmalar ve Yönetim Dergisi(1), 62-79.

14. Cellini, N., Canale, N., Mioni, G., \& Costa, S. (2020). Changes in sleep pattern, sense of time and digital media use during COVID- 19 lockdown in Italy. Journal of Sleep Research, e13074.

15. Chan, E. Y. Y., Huang, Z., Lo, E. S. K., Hung, K. K. C., Wong, E. L. Y., \& Wong, S. Y. S. (2020). Sociodemographic Predictors of Health Risk Perception, Attitude and Behavior Practices Associated with Health-Emergency Disaster Risk Management for Biological Hazards: The Case of COVID-19 Pandemic in Hong Kong, SAR China. International journal of environmental research and public health, 17(11), 3869

16. Chen, T., Wu, D., Chen, H., Yan, W., Yang, D., Chen, G., Ma, K., Xu, D., Yu, H., \& Wang, H. (2020). Clinical characteristics of 113 deceased patients with coronavirus disease 2019: retrospective study. Bmi, 368 .

17. Cirakoglu, O. C. (2011). Domuz Gribi (H1N1) Salgınıyla İlişkili Algıların, Kaygı ve Kaçınma Düzeyi Değișkenleri Bağlamında İncelenmesi. Turk Psikoloji Dergisi, 26(67).

18. Conticini, E., Frediani, B., \& Caro, D. (2020). Can atmospheric pollution be considered a co-factor in extremely high level of SARS-CoV-2 lethality in Northern Italy? Environmental pollution, 114465.

19. Damgacı F, Aydın H. Akademisyenlerin Çokkültürlü Eğitime İlişkin Tutumları. Electronic

20. Journal of Social Sciences. 2013;12(45).

21. Demiray, E. K. D., \& Çeviker, S. A. (2020). Aşı ve Toplumsal Korunma. Journal of Biotechnology and Strategic Health Research, 4, 37-44.

22. Di Renzo, L., Gualtieri, P., Pivari, F., Soldati, L., Attinà, A., Cinelli, G., Leggeri, C., Caparello, G., Barrea, L., \& Scerbo, F. (2020). Eating habits and lifestyle changes during COVID-19 
lockdown: an Italian survey. Journal of Translational Medicine, 18(1), 1-15.

23. Dong, Y., Mo, X., Hu, Y., Qi, X., Jiang, F., Jiang, Z., \& Tong, S. (2020). Epidemiological characteristics of 2143 pediatric patients with 2019 coronavirus disease in China. Pediatrics.

24. Ferguson, N. M., Laydon, D., Nedjati-Gilani, G., Imai, N., Ainslie, K., Baguelin, M., Bhatia, S., Boonyasiri, A., Cucunubá, Z., \& Cuomo-Dannenburg, G. (2020). Report 9 : Impact of non-pharmaceutical interventions (NPIs) to reduce COVID-19 mortality and healthcare demand Https://www.imperial.ac.uk/media/imperialcollege/medicine/sph/ide/gida-fellowships/Imperial-CollegeCOVID19-NPI-modelling-16-03-2020.pdf

25. Ficetola, G. F., \& Rubolini, D. (2020). Climate affects global patterns of COVID-19 early outbreak dynamics. medRxiv.

26. Frontera, A., Martin, C., Vlachos, K., \& Sgubin, G. (2020). Regional air pollution persistence links to covid19 infection zoning. The Journal of Infection.

27. Fu, W., Wang, C., Zou, L., Guo, Y., Lu, Z., Yan, S., \& Mao, J. (2020). Psychological health, sleep quality, and coping styles to stress facing the COVID-19 in Wuhan, China. Translational psychiatry, 10(1), 1-9.

28. Imhoff, R., \& Lamberty, P. (2020). A bioweapon or a hoax? The link between distinct conspiracy beliefs about the Coronavirus disease (COVID-19) outbreak and pandemic behavior.

29. Ioannidis, J. P. A. (2020). Coronavirus disease 2019: The harms of exaggerated information and non-evidence-based measures. European Journal of Clinical Investigation, 50(4), e13222. https://doi.org/10.1111/eci.13222

30. Isphording, I. E., \& Pestel, N. (2020). Pandemic Meets Pollution: Poor Air Quality Increases Deaths by COVID-19.

31. Jarynowski, A., Wójta-Kempa, M., Płatek, D., \& Czopek, K. (2020). Attempt to understand public health relevant social dimensions of COVID-19 outbreak in Poland. Available at SSRN 3570609.

32. Kaparounaki, C. K., Patsali, M. E., Mousa, D.-P. V., Papadopoulou, E. V. K., Papadopoulou, K. K. K., \& Fountoulakis, K. N. (2020). University students' mental health amidst the COVID-19 quarantine in Greece. Psychiatry research, 290, 113111-113111. https://doi.org/10.1016/j.psychres.2020.113111

33. Khan, Y. H., Mallhi, T. H., Alotaibi, N. H., Alzarea, A. I., Alanazi, A. S., Tanveer, N., \& Hashmi, F. K. (2020). Threat of COVID-19 Vaccine Hesitancy in Pakistan: The Need for Measures to Neutralize Misleading Narratives. The American journal of tropical medicine and hygiene, tpmd200654.

34. Kwok, K. O., Li, K. K., Chan, H. H., Yi, Y. Y., Tang, A., Wei, W. I., \& Wong, S. Y. S. (2020). Community responses during early phase of covid-19 epidemic, Hong Kong. Emerg Infect Dis, 26(7), 10.3201.

35. Lau, L. L., Hung, N., Go, D. J., Ferma, J., Choi, M., Dodd, W., \& Wei, X. (2020). Knowledge, attitudes and practices of COVID-19 among income-poor households in the Philippines: A cross-sectional study. Journal of global health, 10(1).

36. Li, W., Shi, Z., Yu, M., Ren, W., Smith, C., Epstein, J. H., Wang, H., Crameri, G., Hu, Z., \& Zhang, H. (2005). Bats are natural reservoirs of SARS-like coronaviruses. Science, 310(5748), 676-679.

37. Mattioli, A. V., Sciomer, S., Cocchi, C., Maffei, S., \& Gallina, S. (2020). Quarantine during COVID-19 outbreak: changes in Diet and physical activity increase the risk of cardiovascular disease. Nutrition, Metabolism and Cardiovascular Diseases.
38. Miller, J. M. (2020). Psychological, Political, and Situational Factors Combine to Boost COVID-19 Conspiracy Theory Beliefs. Canadian Journal of Political Science/Revue canadienne de science politique, 1-8.

39. Özdin, S., \& Bayrak Özdin, Ş. (2020). Levels and predictors of anxiety, depression and health anxiety during COVID-19 pandemic in Turkish society: The importance of gender. International Journal of Social Psychiatry, 0020764020927051.

40. Patsali, M. E., Mousa, D.-P. V., Papadopoulou, E. V. K., Papadopoulou, K. K. K., Kaparounaki, C. K., Diakogiannis, I., \& Fountoulakis, K. N. (2020). University students' changes in mental health status and determinants of behavior during the COVID-19 lockdown in Greece. Psychiatry research, 292 , 113298. https://doi.org/https://doi.org/10.1016/j.psychres.2020.113298

41. Peçanha, T., Goessler, K. F., Roschel, H., \& Gualano, B. (2020). Social isolation during the COVID-19 pandemic can increase physical inactivity and the global burden of cardiovascular disease. American Journal of Physiology-Heart and Circulatory Physiology, 318(6), H1441-H1446.

42. Reuben, R. C., Danladi, M. M., Saleh, D. A., \& Ejembi, P. E. (2020). Knowledge, Attitudes and Practices Towards COVID19: An Epidemiological Survey in North-Central Nigeria. Journal of community health, 1-14.

43. Reyes-Olavarría, D., Latorre-Román, P. Á., Guzmán-Guzmán, I. P., Jerez-Mayorga, D., Caamaño-Navarrete, F., \& DelgadoFloody, P. (2020). Positive and Negative Changes in Food Habits, Physical Activity Patterns, and Weight Status during COVID-19 Confinement: Associated Factors in the Chilean Population. International Journal of Environmental Research and Public Health, 17(15), 5431.

44. Saadat, S., Rawtani, D., \& Hussain, C. M. (2020). Environmental perspective of COVID-19. Science of The Total Environment, 138870

45. Sidor, A., \& Rzymski, P. (2020). Dietary Choices and Habits during COVID-19 Lockdown: Experience from Poland. Nutrients, 12(6), 1657.

46. Straif-Bourgeois, S., \& Robinson, W. (2020). About Coronavirus Disease 2019 (COVID-19). Journal of Health Care Finance.

47. Wassenaar, T. M., \& Zou, Y. (2020). 2019_nCoV/SARS- CoV- 2: rapid classification of betacoronaviruses and identification of Traditional Chinese Medicine as potential origin of zoonotic coronaviruses. Letters in Applied Microbiology, 70(5), 342-348.

48. WHO. (2020). COVID-19, Questions and answers. http://www.emro. who.int/health-topics/corona-virus/questionsand-ans wers.html.

49. Yang, P., \& Wang, X. (2020). COVID-19: a new challenge for human beings. Cellular \& Molecular Immunology, 17(5), 555557. https://doi.org/10.1038/s41423-020-0407-x

50. Yang, Y., Peng, F., Wang, R., Guan, K., Jiang, T., Xu, G., Sun, J., \& Chang, C. (2020). The deadly coronaviruses: The 2003 SARS pandemic and the 2020 novel coronavirus epidemic in China. Journal of autoimmunity, 102434.

51. Yılmaz, S. (2020). COVID-19'u kim üretti? Aşısı ne zaman bulunacak?.. 25 Mart 2020 Giriș. Policy.

52. Ziemba, E. (2020). Information Technology for Management: Current Research and Future Directions. In 17th Conference on Advanced Information Technologies for Management (Vol. 380). S 